\title{
CINEMA, ESPORTE E APARTHEID: CONSIDERAÇÕES BALIZADAS PELO FILME MORE THAN JUST A GAME
}

\author{
Cinema, sport and Apartheid: considerations \\ based on the film More than just a game
}

Cine, deportes y Apartheid: consideraciones basadas en la película More than just a game

\author{
Riqueldi Straub Lise* \\ André Mendes Capraro* \\ Natasha Santos*
}

\begin{abstract}
RESUMO
A presente pesquisa consiste na análise do filme No futebol, nasce uma esperança (originalmente More Than Just a Game), cujo foco está na prática do futebol por prisioneiros políticos sul-africanos, durante o regime Apartheid. Tendo em pauta esta temática questiona-se: seria o futebol realmente um meio propício para manifestações políticas contrárias ao sistema vigente na África do Sul - o regime Apartheid? Qual o significado da modalidade, naquele contexto específico, e como foi representado artisticamente na obra? Para responder a essas questões, adotou-se o procedimento metodológico denominado por Carlo Ginzburg (1996) de "paradigma indiciário". Assim, o esforço foi na busca de pistas e indícios que levassem a compreender melhor a concepção histórica manifesta no filme. Nesse sentido, pode-se inferir que o ocorrido na prisão da Ilha de Robben, por meio da (re)estruturação do enredo, superdimensiona a prática do futebol entre os presos e até mesmo o grau de importância destes no processo geral de tensões ocorridas durante o regime segregacionista em questão. Enfim, como
\end{abstract}

${ }^{*}$ UFPR. 
"gênero de fronteira" o filme é tendencioso ao atender a interesses recentes - a Copa do Mundo 2010.

Palavras-chave: cinema; futebol; Apartheid.

\begin{abstract}
The present research consists in the analysis of the movie More Than Just a Game, whose focus is the soccer's practice by the politicians South African prisoners, during the Apartheid regimen. In this context, it is questioned: would be the soccer really a propitious way for politics manifestations against the effective system in the South Africa - the Apartheid regimen? Which is the meaning of the modality, in that specific context, and how it was represented artistically in the film? For answering to these questions, it was adopted the methodological procedure from Carlo Ginzburg (1996), the "indiciary paradigm". Thus, the effort was in the search of tracks and indications that could lead to a better comprehension about the historical conception showed in the movie. In this direction, it can be inferred that the occurrence in the Robben Island prison, by the (re)construction of the story, amplifies the soccer's practice among the prisoners, and even the degree of importance of these in the general process of tensions during Apartheid. At last, as a "border gender" the film is tendentious when it takes care of the recent interests - the 2010 World Cup.
\end{abstract}

Key-words: cinema; soccer; Apartheid.

\title{
RESUMEN
}

La presente pesquisa es el análisis de la película More Than Just a Game, cuya atención se centra en la práctica de fútbol por los presos políticos en Sudáfrica durante el régimen del Apartheid. Con este tema la pregunta es: el fútbol realmente seria un medio ambiente propicio para las manifestaciones políticas contra el sistema imperante en Sudáfrica - el régimen del Apartheid? Cuál es el significado del deporte en ese contexto específico, y como fue artísticamente representado en la obra? Para responder a estas preguntas, hemos adoptado el procedimiento metodológico llamado por Carlo Ginzburg (1996) el "paradigma indiciário". Así, el esfuerzo fue en busca de pistas y pruebas que podrían conducir a una mejor comprensión de la concepción histórica que se manifiesta en la película. En este sentido, se puede concluir que lo que pasó en la prisión de Robben Island, a través de la (re)estructuración de la trama, aumenta fuertemente la práctica de fútbol entre los penitenciarios y incluso el grado de importancia de ellos en el proceso en general de estrés que se produjeron durante el régimen del Apartheid en cuestión. 
De todos modos, como "gênero de fronteira", la película es parcial para atender a los intereses recientes - la Copa Mundial 2010.

Palabras-clave: Cine, Fútbol, Apartheid.

\section{Introdução}

Em 2007, sob a direção de Junaid Ahmed, foi lançado em circuito mundial o longa metragem More Than Just a Game (em português, No futebol, nasce uma esperança). Em síntese, a obra apresenta um estudo de caso: o de um grupo de prisioneiros políticos sul-africanos que, por meio da prática do futebol na prisão da Ilha de Robben, exprimia sentimentos diversos como liberdade, autorregulação, rebeldia (sempre controlada), fidalguia, dignidade, entre outros.

Relevando-se que o filme é uma produção artística ${ }^{1}$ e que toda forma de arte guarda sua autonomia ${ }^{2}$, objetiva-se analisar como a obra cinematográfica em questão (re)interpreta a prática do futebol pelos prisioneiros da Ilha de Robben, com ênfase na forma como foi manifesta a confluência entre o esporte e a política local, tendo como parâmetro que a produção foi feita às vésperas da Copa do Mundo de 2010. Fundidas à criação artística fílmica, apresentam-se nuances - ora sutis, ora evidentes - da produção de um sentido que visava elevar a prática do futebol a um modo de manifestação política. Porém, ao seguir alguns "indícios e pistas", como proposto por Ginzburg ${ }^{3}$, acerca do episódio histórico ocorrido na Ilha de Robben, é possível problematizar algumas das concepções ideológicas manifestas no filme - o futebol como meio de contestação e/ou alienação; o nível de aceitação entre os presos; e os interesses dos produtores.

Assim, emergem as seguintes questões: seria o futebol realmente um meio propício para manifestações políticas contrárias ao sistema vigente na África do Sul - o regime Apartheid? Ou seria apenas uma prática

2006.

1 MELO, V. A.; ALVITO, M. (Orgs). Futebol: diálogos com o cinema. Rio de Janeiro: FGV, Queiroz, 2000

2 CANDIDO, A. Literatura e sociedade: estudos de teoria e história literária. São Paulo:

3 GINZBURG, C. A micro-história e outros ensaios. Lisboa: Difel, 1989. 
doutrinária, uma concessão do sistema prisional? Tal prática esportiva era, realmente, um elemento pacífico ao grupo de presos, como apresentado no filme? Qual o significado da modalidade, naquele contexto específico, e como foi representado artisticamente na obra?

Visando responder às questões-problema acima apresentadas, partir-se-á da hipótese de que a conjuntura sociopolítico-esportiva na África do Sul (mesmo em um espaço específico, como um presídio), sob a égide do sistema de segregação racial presente na década de 1960, era complexa demais para que a prática organizada de uma única modalidade esportiva pudesse ser considerada uma forma de protesto e indignação, relevantes no cenário mais amplo. Em contrapartida, naquele locus específico, o esporte era capaz de mostrar que um grupo seleto de prisioneiros poderia apresentar alto poder organizativo e hierárquico. Em última instância, como criação do seu próprio tempo (2007), já desvelado o aspecto geral deste episódio histórico, a obra apresenta interesses atuais - sejam eles de propaganda política ou esportiva.

No que se refere à remota relação entre cinema e História, a produção a ser analisada no presente estudo pode ser definida como o gênero "filme histórico", isto é, uma produção que carrega como temática um fato histórico - neste caso, as consequências pela implementação do Apartheid na África do Sul. Apropriando-se das ideias lançadas por Nova ${ }^{5}$, o fato de refletir interesses atuais possibilita que a obra em questão seja classificada como um filme de caráter documental secundário, a qual acaba por abordar mais intrinsecamente o presente, embora o discurso transmitido esteja centrado em um determinado contexto histórico.

Ao submeter o enredo do filme à comparação com a biografia dos principais agentes envolvidos (tanto os protagonistas da história quanto a equipe técnica e os financiadores), bem como com a produção bibliográfica acerca da temática, adotando como prática o uso do campo hipotético, adotou-se o procedimento metodológico denominado por Carlo Ginzburg ${ }^{6} \mathrm{de}$ "paradigma indiciário". Assim, o esforço foi na busca de pistas e indícios que levassem a compreender melhor a concepção histórica manifesta no filme.

4 NOVA, Cristiane. O cinema e o conhecimento da História. O Olho da História: revista de história contemporânea, Salvador, v. 2, n. 3. 1996.

5 Id., ibid.

6 GINZBURG, C. Mitos, emblemas, sinais: morfologia e história. São Paulo: Companhia das Letras, 1996. 


\section{O contexto sociopolítico da África do Sul a partir da década de 1960: Apartheid e resistência}

Em 1948, o National Party (NP) assume a presidência da África do Sul e institucionaliza o regime Apartheid (política de segregação racial), sob a alegação de proteger a identidade sociocultural branca ${ }^{7}$. Como principal efeito desse sistema, houve a subtração dos direitos sociais, econômicos e políticos dos negros, isto é, da maioria da população africana ${ }^{8}$. O governo inicia, assim, uma forte repressão aos partidos opositores, dentre os quais se destacavam o African National Congress (ANC) e o Pan Africanist Congress (PAC).

Nessa conjuntura, em 21 de março de 1960, ocorreu um episódio considerado trágico pela imprensa, bem como por instituições internacionais que primavam pelos direitos civis: o Massacre de Sharpeville. Cerca de cinco mil manifestantes protestavam pacificamente contra leis que os proibiam de circular pelo seu próprio país (a "lei do passe"). Entretanto, a polícia interveio de modo violento e o protesto foi reprimido a tiros. Sessenta e nove manifestantes morreram e aproximadamente 200 ficaram feridos, dentre eles estudantes, mulheres e crianças ${ }^{9}$. Mesmo passados mais de 45 anos, o antigo secretário geral das Nações Unidas, Kofi Annan, não hesitou em citar a atrocidade em questão, ao tratar do que chamou de "vírus do racismo":

Forty-five years ago today, 69 demonstrators were shot and killed in the Sharpeville massacre, during a non-violent protest against apartheid. Each year, the United Nations marks this anniversary by drawing special attention to the continuing fight against all forms of racial discrimination.[...] As we remember the sacrifices of Sharpeville, and the sufferings and victories of people across the years and around the world in combating racism, let us today heed the call

7 PEREIRA, F. J. Apartheid: o horror branco na África do Sul. São Paulo: Brasiliense, 1985.

8 JONGE, K. de. África do Sul: Apartheid e resistência. São Paulo: Cortez/Eboh, 1991.

9 WINNER, David. Desmond Tutu. São Paulo: Globo, 1993. 
of the Universal Declaration of Human Rights, to "reaffirm faith in fundamental human rights, in the dignity and worth of the human person, and in the equal rights of men and women"10.

Relembrado anualmente, aos 21 dias do mês de março (Dia dos Direitos Humanos), esse evento atroz marca a imediata mudança de postura dos partidos opositores que, até então, se organizavam de forma pacífica frente ao regime Apartheid ${ }^{11}$. Nelson Mandela, um dos principais líderes do ANC, passou a coordenar campanhas de treinamentos paramilitares e sabotagens, estabelecendo-se a luta armada na África do Sul. Assim, aquele que mais tarde se tornaria um ícone do pacifismo mundial, quando jovem, poderia ser considerado de acordo com o posicionamento de quem o observava como um revolucionário ou terrorista: “A 16 de dezembro de 1961 atos de sabotagem marcaram o surgimento do Umkhonto we Sizwe (Lança da Nação), que se tornaria mais tarde o braço armado do ANC. Mandela foi membro-fundador e comandante-chefe do Umkhonto (MK)"12.

Em 1961, todos os partidos políticos contrários ao Apartheid passaram a ser considerados ilegais; seus ativistas foram julgados e a maioria foi condenada à prisão - dependendo do caso, a pena pelo crime político poderia chegar até o enforcamento ${ }^{13}$. Nesse contexto, milhares de condenados por esse tipo de delito foram encarcerados na prisão da Ilha de Robben, localizada a aproximadamente oito quilômetros da Cidade do Cabo e conhecida, também, como a Alcatraz da África.

10 ANNAN, K. "No one can be neutral" on fight against virus of racism. United Nations, 2005. Disponível em: <http://www.un.org/News/Press/docs/2005/sgsm9765.doc.htm>. Acesso em: 08/03/2010. Tradução Natasha Santos: "Há quarenta e cinco anos atrás, 69 manifestantes receberam disparos e foram mortos no massacre de Sharpeville, durante um protesto não violento contra o Apartheid. Todos os anos, as Nações Unidas marcam esse aniversário chamando atenção para a contínua luta contra todas as formas de discriminação racial. [...] A lembrança dos sacrifícios de Sharpeville, bem como do sofrimento e das vitórias dos povos ao longo dos anos e pelo mundo inteiro no combate ao racismo, nos permite, hoje, atentar para o chamado da Declaração Universal dos Direitos Humanos, para 'reafirmar a fé nos direitos humanos fundamentais, na dignidade e no valor do ser humano, e nos direitos iguais entre homens e mulheres"".

11 VAIL, J. J. Winnie e Nelson Mandela. São Paulo: Nova Cultural, 1988.

12 MANDELA, N. A luta é minha vida. Rio de Janeiro: Globo, 1988.

13 Id., ibid. 
É este o cenário em que figura o filme No futebol, nasce uma esperança. A Ilha de Robben chegou a abrigar mais de 1.400 presos simultaneamente e dentre eles havia detentos políticos e criminosos comuns, negros em sua maioria, os quais eram submetidos a trabalhos forçados na pedreira da ilha. As condições carcerárias eram débeis e o tratamento dispensado aos presos era extremamente violento: mortes decorrentes de torturas não eram fatos raros. Prova disso é o depoimento de Johnson Mlambo, detido na Ilha de Robben entre os anos de 1963 e 1983, segundo o qual, nos seus primeiros anos na prisão, era comum "Ser enterrado até o pescoço e ter prisioneiros simplesmente desaparecendo" 14 . Entretanto, graças a intervenções por parte da Cruz Vermelha, esse cenário começou a mudar.

Como será melhor detalhado, não foram essas as condições dos prisioneiros protagonistas da obra em questão. Devido aos excessos de violência, e já que a ilha era símbolo da repressão política vigente na África do Sul, organizações de direitos civis voltaram seus olhos à ilha, preocupadas com as condições sub-humanas e as arbitrariedades às quais os presos eram submetidos ${ }^{15}$. Após a condenação e a prisão dos principais articuladores do movimento anti-Apartheid - dentre eles Nelson Mandela, Ahmed Kathrada, Walter Sisulu e Oliver Tambo -, o autoritarismo sul-africano tornou-se notório, desencadeando reações dessas entidades na luta pelos direitos humanos ${ }^{16}$. A modo de exemplo, pode-se citar a Cruz Vermelha - que exigiu a presença de inspetores com a finalidade de impedir o tratamento inadequado aos pre$\operatorname{sos}^{17}$; a Organização das Nações Unidas (ONU) - que, em 6 de novembro de 1962, condenou as políticas segregacionistas do Apartheid, impondo à África do Sul sanções políticas e econômicas ${ }^{18}$; e a Federação Internacional de Futebol Associado (FIFA), em específico, por ser constantemente usada

14 CICV. África do Sul: vozes da Ilha de Robben. Visitas do CICV aos detidos: ex-detidos compartilham suas experiências. CICV, 2004. Disponível em: $<$ http://www.icrc.org/web/por/sitepor0.nsf/ htmlall/detention_testimonies_040713?OpenDocument\&style $=$ Custo_Final\&View $=$ defaultBody $8>$. Acesso em: 30/01/ 2010 .

15 MANDELA, N. A luta é minha vida, op. cit.

16 MAHARAJ, M. (Ed.). Mandela: retrato autorizado. São Paulo: Alles Trade, 2007.

17 CICV. África do Sul: vozes da Ilha de Robben, op. cit.

18 UN Chronicle. The Long Road to Durban: The United Nations Role in Fighting Racism and Racial Discrimination. Disponível em: <http://www.un.org/wcm/content/site/chronicle/cache/bypass/ lang/en/home/archive/issues2007/thesolidarityofpeoples/thelongroadtodurban?pagination=true\&ctnscro 11_articleContainerList=1_2\&ctnlistpagination_articleContainerList=true $>$.Acesso em: 03/02/2010. 
como referência pelos praticantes de futebol na ilha - que proibiu a África do Sul de participar de competições oficiais da modalidade.

Outro importante acontecimento político-social que desencadearia novos confrontos entre o governo da África do Sul e a população negra teve início em 1974. O NP decretou uma nova lei com caráter segregacionista, a qual tornava obrigatória a adoção do idioma africânder em todas as escolas do país. O idioma era utilizado principalmente pelas classes brancas dominantes e, sendo assim, tal imposição desagradou à maioria negra, sobretudo pela falta de identidade cultural com o africânder, considerado a "língua branca". Essa impopularidade quanto à adoção do sistema de educação Bantu às escolas ocasionou uma série de protestos contra a determinação forçosa do Estado, os quais culminaram com o Levante do Soweto ${ }^{19}$, região com predominância de operários negros, e onde o futebol é muito popular, considerando que os três maiores clubes do país estão ali sediados. São eles o Moroka Swallows, Orlando Pirates e Kaizer Chiefs. O Soweto foi palco de um dos maiores massacres ocorridos durante o regime Apartheid $^{20}$. No dia 16 de junho de 1976, estudantes organizaram um protesto, cujo objetivo era marchar pacificamente pelas ruas de Johannesburgo, porém, mais uma vez, a repressão da polícia local foi violenta e resultou em centenas de mortes, dentre eles, adultos, mulheres e jovens estudantes ${ }^{21}$. $\mathrm{O}$ fato ganhou notoriedade nos noticiários de todo o mundo, desgastando ainda mais a imagem do governo racista da África do Sul. Em consequência disso, o dia 16 de junho é até hoje considerado o dia da juventude naquele país. Já nos demais países, a data é lembrada por meio de notícias que retomam o ocorrido: "Calcula-se que mais de 500 estudantes tenham morrido quando a polícia abriu fogo contra eles. A imagem de Hector Piterson, ferido mortalmente aos 13 anos, correu o mundo"22.

A partir de 1976, o descontentamento da maioria da população negra com o aumento da repressão policial imposta pelo Partido Nacional

19 VAIL. Winnie e Nelson Mandela, op. cit.

20 FIFA. S de Soweto. A-Z da áfrica do Sul. Disponível em: <http://pt.fifa.com/worldcup/ destination/southafricafromatoz/index.html>. Acesso em: 26/11/2009.

21 WINNER. Desmond Tutu, op. cit.

22 FOLHA ONLINE. África do Sul relembra episódio que precipitou o fim do Apartheid. 16 jun. 2009. Disponível em: <http://www1.folha.uol.com.br/folha/bbc/ult272u582068.shtml>. Acesso em: $16 / 06 / 2009$. 
resultou em uma onda de protestos e na organização de inúmeros comitês anti-Apartheid - alguns admitiam até a resistência armada ${ }^{23}$. Com a ascensão de Pieter Willen Botha ao cargo de primeiro-ministro, no ano de 1978, deu-se início ao período mais sangrento na luta pela igualdade sociorracial na África do Sul. Militantes de organizações antigovernistas foram presos e, em alguns casos, mortos em situações suspeitas. Essa prática, no entanto, já havia sido utilizada pelo regime em anos anteriores, conforme explicitado pelo relato do ex-detento da ilha de Robben, Johnson Mlambo, que afirmou que alguns prisioneiros desapareciam misteriosamente ${ }^{24}$.

O período compreendido entre 1978 e 1989 ficou marcado como o mais instável do regime de Apartheid. O governo de Botha reagia com violência aos atentados de organizações contrárias à situação política vigente: inúmeros protestos, greves ou manifestações foram severamente repreendidos pelo aparato governista. A prisão de Robben continuava sendo o destino dos opositores ao regime, o próprio filme No futebol, nasce uma esperança faz alusão à chegada de grupos de estudantes detidos em tais manifestações. "Eram soldados com uniformes escolares. Eles lutaram bravamente contra a polícia. Eles foram presos em bandos e mandados para a ilha", frisou Lizo Sitoto em depoimento ${ }^{25}$.

Em 1989, com problemas de saúde, Pieter Willen Botha deixa a presidência e Frederik Willen De Klerk assume tal posto. A África do Sul encontrava-se à beira de uma guerra civil e as consequências das sanções políticas e comerciais, impostas por organizações internacionais, se faziam cada vez mais presentes ${ }^{26}$. O sistema segregacionista, conduzido pelo Partido Nacional, já não reunia as condições necessárias para manter as políticas vigentes até então.

Em 1990, De Klerk, em seu célebre discurso no parlamento sul-africano, anuncia importantes mudanças na conduta política do país e declara a legalidade dos partidos oposicionistas, bem como a libertação de

23 CEZIMBRA, S. D. Movimentos de Resistência ao Regime de Apartheid na África do Sul: uma análise sobre a imprensa gaúcha. Monographia, Porto Alegre, n. 1, 2005. Disponível em: <http:// www1.fapa.com.br/monographia/php/home.php?pag=4\&img=8>. Acesso em: 20/02/2010.

24 CICV. África do Sul: vozes da Ilha de Robben, op. cit.

25 AHMED, J.; SINGH, A. More Than Just a Game. [Filme]. Produção de Anant Singh, direção de Junaid Ahmed. África do Sul: Distant Horizont, 2007. 89 min.

26 JONGE. África do Sul: Apartheid e resistência, op. cit. 
presos políticos, dentre os quais, Nelson Mandela ${ }^{27}$. Quatro anos após sua libertação, Mandela assume a presidência da África do Sul nas primeiras eleições livres do país, com a proposta de revogar as leis segregacionistas e tornar a nação sul-africana mais justa e democrática, devolvendo à maioria negra direitos que lhes haviam sido tomados durante o regime autoritário do Apartheid. Mesmo após o término do seu mandato como presidente da África do Sul, Mandela segue na luta contra as heranças socioculturais deixadas pelas políticas racistas que conduziram o país durante décadas. Sua reputação e seu envolvimento em questões conciliadoras tornaram-no um dos principais articuladores da candidatura da África do Sul a país-sede da Copa do Mundo de 2010 - a cena final do documentário retrata exatamente a cerimônia na qual a FIFA anuncia que a Copa de 2010, pela primeira vez, se realizaria na África do Sul.

\section{Making off: técnica cinematográfica, criação artística e seus financiadores}

Marc Ferro ${ }^{28}$, já na década de 1960, alertava que o historiador deve buscar no filme o que não está visível, já que a obra cinematográfica excede seu próprio conteúdo. Isto é, “[...] o filme revela aspectos da realidade que ultrapassam o objetivo do realizador, além de estar expressa uma ideologia da sociedade em foco" 29 . Soma-se a isso a relação da obra com a sociedade que o produz/consome, articulando realização, audiência, financiamento. Ou seja, variáveis não cinematográficas (condições de produção, censura) devem ser levadas em consideração pelo historiador, junto à própria especificidade da expressão cinematográfica. E, nesse sentido, faz-se imprescindível pensar o lugar no mundo, o lugar de onde o discurso cinematográfico é

27 MAHARAJ, M. (Ed.). Mandela: retrato autorizado, op. cit.

28 FERRO, M. O filme, uma contra-análise da sociedade? In: LE GOFF, J.; NORA, P. História: novos objetos. 3 ed. Rio de Janeiro: Francisco Alves, 1988.

29 KORNIS, M. A. História e cinema: um debate metodológico. Estudos Históricos, Rio de Janeiro, v. 5, n. 10, p. 245, 1992. 
constituído, o que nega qualquer tipo de neutralidade quanto aos métodos de produção, isto é, mesmo a neutralidade seria uma atitude política ${ }^{30}$.

A técnica utilizada no filme consistiu no estabelecimento de um enredo temporalmente linear, narrando a vida dos protagonistas na prisão, sob a égide do regime Apartheid, e destacando a presença significativa do esporte (o futebol) no cotidiano carcerário. Tal narrativa foi ambientada na prisão/ pedreira da Ilha de Robben, próxima à Cidade do Cabo - o próprio Nelson Mandela foi um dos presos, como de relance é exposto no documentário.

A Ilha de Robben já serviu de parada na rota comercial marítima, estabelecida pelos holandeses com destino à Índia; mais tarde, funcionou como um asilo para leprosos e portadores de deficiências mentais ${ }^{31}$; e, por fim, na década de 1960, figurou como símbolo do autoritarismo do Apartheid, período em que se passa o filme. Após o recrudescimento de tal regime, a prisão foi desativada e transformada em museu. A ilha foi, ainda, declarada pela UNESCO como patrimônio da humanidade, tornando-se um ponto turístico bastante visitado. Entretanto, o filme No futebol, nasce uma esperança não foi o primeiro a se utilizar desse patrimônio: Robben já servira de cenário para outras produções cinematográficas, dentre elas, Prisoners of Hope, do mesmo produtor, Anant Singh, cuja temática também gira em torno da ilha como expoente do autoritarismo político e segregacionista.

Intercalados ao enredo, são exibidos depoimentos, no formato de entrevistas, dos personagens de destaque no filme, sendo eles: Anthony Suze, que cumpriu pena de 15 anos e hoje é diretor de uma empresa comercial em Pretória; Mark Shinners, condenado a 20 anos, foi um dos congressistas responsáveis pela primeira constituição democrática da África do Sul; Lizo Sitoto, recluso por 10 anos, atualmente é membro fundador e diretor de um novo modelo educacional para as escolas sul-africanas; Sedick Isaacs, condenado a 13 anos de reclusão, concluiu doutorado em 1990 e hoje é professor da Universidade de Medicina da Cidade do Cabo; e Marcus Solomon, recluso durante 10 anos, hoje coordena uma organização que destina recursos para projetos sociais que beneficiam as crianças carentes da África do Sul. 
Nesse sentido, a obra pode ser considerada um "gênero de fronteira"32, já que, embora pautada em uma história real, (re)construída pelos próprios agentes envolvidos, é interpretada artisticamente por um elenco de atores profissionais, aproximando-se do que é considerado, pelos críticos, um gênero cinematográfico definido como drama; entretanto, assemelha-se, também, a outro gênero, o documentário, uma vez que expõe variados depoimentos dos ex-presos políticos. Diante de tais características, pode-se dizer que More Than Just a Game se classificaria como sendo um "docudrama", ou seja, um filme baseado em fatos reais que, ao mesmo tempo em que se aproxima do documentário, com o respaldo de entrevistas, é dramatizado por atores profissionais - aproximando-se também da ficção ${ }^{33}$.

Há de se destacar o cuidado da direção para que não ocorresse nenhuma espécie de rompimento entre a interpretação cênica e os depoimentos. Com o esmero técnico - luz/sombra, expressões faciais, posicionamento e foco-, os depoimentos soavam como reflexões (amadurecidas) dos próprios personagens, tendo em vista que o enredo corresponde ao período em que estes estiveram na prisão: ainda na década de 1960, quando a maioria deles estava no auge da juventude. Assim, mesmo como "gênero de fronteira", oscilando entre o drama e o documentário, o filme foi constituído de um modo que impedisse rompimentos que pudessem prejudicar a tensão oferecida ao espectador.

A articulação dessa apresentação fílmica, a partir de um determinado local (a África do Sul), em um determinado período (o regime Apartheid), só pode ser compreendida por meio do mapeamento dos indivíduos envolvidos com a produção da obra, bem como dos seus financiadores, já que, segundo Nóvoa: “A realidade-ficção do cinema promove, de fato, as leituras e interpretações das camadas sociais que, direta ou indiretamente, controlam os meios de produção cinematográfica" ${ }^{34}$.

O diretor da obra analisada, Junaid Ahmed, é um conceituado produtor e diretor de cinema e televisão. Em seu currículo, constam diversas

32 VELOSO, M.; MADEIRA, A. Leituras brasileiras: itinerários no pensamento social e na literatura. São Paulo: Paz e Terra, 1999.

33 ROSENTHAL, A. (Ed.). Why docudrama? Fact-fiction on film and TV. Carbondale: Southern Illinois University Press, 1999.

34 NÓVOA, J. Apologia da relação cinema-história. O olho da História, Salvador, v. 1, n. 1, p. $105-116,1998$. 
produções televisivas, destacando-se alguns documentários para canais internacionais, entre estes o Discovery Channel. Possui, ainda, uma vasta produção cinematográfica: suas obras arrebataram diversas premiações em festivais internacionais, podendo-se citar Iqakamba - Hard Ball, considerado o melhor documentário de esportes no festival de Milão no ano de 1996, e Lucky, um curta-metragem premiado em mais de 30 festivais internacionais em 2006. Engajado politicamente e preocupado com questões sociais referentes à África do Sul, Ahmed tornou-se participante ativo de comitês consultivos, conselhos de administração pública ou privada e atuou em diversas organizações não governamentais. Tais atividades o credenciaram a ocupar a cadeira de Secretário-Geral do Congresso Sul-Africano de Escritores (COSAW), representando esta entidade em inúmeras conferências, além de publicar uma série de artigos cujas temáticas enfocam questões culturais e artísticas da África do Sul. Em 1996, o ministro sul-africano de Artes e Cultura nomeou Junaid Ahmed presidente da National Film Board, hoje a atual National Film and Video Foundation (NFVF), instituição esta que figura entre os patrocinadores da obra em questão ${ }^{35}$.

O responsável pela produção do filme foi o sul-africano Anant Singh. Intensamente envolvido com questões políticas, sua carreira cinematográfica ganhou notabilidade pela constante presença da temática anti-Apartheid: produziu aproximadamente 60 filmes desde 1984, os quais desvelam a África do Sul sob o regime totalitário do Apartheid. Sua filmografia inclui os dois maiores sucessos de bilheteria da história da África do Sul - a comédia Mr. Bones e Mama Jack. Considerado pela crítica especializada como o produtor mais completo daquele país, Singh recebeu do próprio Nelson Mandela a autorização para filmar sua autobiografia, sob o título de Long Walk To Freedom. O produtor também ganhou vários prêmios internacionais com Serafina!, Cry, The Beloved Country e Yesterday - primeiro filme sul-africano a receber indicação para o prêmio da Academia (Oscar), na categoria de melhor filme estrangeiro no ano de 2005. Anant Singh é membro da diretoria do Conselho International de Marketing da África do Sul e o único representante sul-africano da Academia de Ciências e Artes

35 PRODUCTION NOTES. More Than Just a Game. Junaid Ahmed. Disponível em: < http:// www.morethanjustagame.co.za/junaid.html>. Acesso em: 21/02/2010. 
de Imagem em Movimento; foi fundador da Videovision, empresa esta que participou da produção do filme tratado nesta pesquisa ${ }^{36}$.

A distribuição de No futebol, nasce uma esperança foi elaborada pela United National Video, uma referência na indústria cinematográfica mundial, fundada em 1981 e sediada em Londres ${ }^{37}$. A produção da obra, por sua vez, ficou sob a responsabilidade da Videovision Entertainment companhia sul-africana especializada em produzir filmes que destacam questões referentes ao próprio país, embora sem deixar de visar à atratividade internacional; sua tendência é mostrar um país em desenvolvimento, após a superação do grande obstáculo que foi o Apartheid. Nesse sentido, a coprodução do filme foi realizada pela Distant Horizon, empresa subsidiária da Videovision Entertainment ${ }^{38}$.

A companhia Telkom Media, sediada na própria África do Sul, se faz presente como patrocinadora do filme. A empresa é líder no mercado de linhas telefônicas fixas e móveis no país, além de ser a maior provedora de banda larga e deter direitos exclusivos na exploração de transmissões via satélite e a cabo ${ }^{39}$. Tais características comerciais tornam a Telkom uma das grandes interessadas na realização da Copa do Mundo na África do Sul, justificando, portanto, seus investimentos em produções cinematográficas desta natureza.

A National Film and Video Foundation (NFVF) é o órgão oficial do governo sul-africano que disponibiliza fundos às áreas de produção, distribuição e marketing de longas-metragens e programas de televisão. A missão deste órgão é estimular produções das comunidades negras que, durante a vigência do regime Apartheid, estiveram à margem desse tipo de atividade. Em 2005, os investimentos somaram a quantia de aproximadamente 28 milhões de randes (4 milhões e meio de dólares). Porém, em 2007, ano do lançamento do filme em questão, os investimentos alcançaram as cifras de quase 47 milhões de randes ( 6 milhões e meio de dólares $)^{40}$. É provável que

36 PRODUCTION NOTES. More Than Just a Game. Anant Singh. Disponível em: < http:// www.morethanjustagame.co.za/junaid.html>. Acesso em: 21/02/2010.

37 UNITED INTERNATIONAL PICTURES. Disponível em: $<$ http://www.uip.com/>. Acesso em: 15/03/2010.

38 PRESS RELEASES. More Than Just a Game. Disponível em: < http://www.morethanjustagame.co.za/pr_4.html>. Acesso em: 21/02/2010.

39 TELKOM MEDIA. Disponível em: <http://www.telkom.co.za/>. Acesso em: 19/03/2010.

40 FILME B. Disponível em: <www.filmeb.com.br/dbmundo/html/africa.php >. Acesso em: $21 / 03 / 2010$. 
esse aumento significativo tenha relação direta com o financiamento do filme e, consequentemente, com a campanha publicitária para a Copa do Mundo.

Como bem sugere Ginzburg ${ }^{41}$, é parte fundamental do ofício do pesquisador das ciências sociais seguir os indícios: 1) a Telkom é, indubitavelmente, interessada na realização da Copa do Mundo de futebol na África do Sul, por motivos óbvios, como o fato de ser detentora exclusiva dos direitos de transmissão, por exemplo; 2) o aumento substancial nos investimentos da NFVF se deu justamente enquanto a FIFA deliberava sobre qual seria a sede da Copa do Mundo de 2010, período no qual as produções sobre futebol e documentários de heróis do movimento anti-Apartheid vieram à tona, culminando com a assertiva de que o país realmente sediaria o evento, já que o próprio filme em questão encerra com o anúncio definitivo da FIFA.

Outra importante característica desta obra cinematográfica, relatada pelo produtor do filme em entrevista, é o fato de a FIFA tê-la endossado. Segundo Singh (2007), esta produção referenda o ideário da entidade, norteado pelos princípios da inclusão, rigores técnicos, fair play, disciplina coletiva e comprometimento com a excelência. É por isso que o produtor fez questão de enfatizar na produção do filme que os atletas/presos se preocupavam tanto em implementar as normas oficiais da FIFA, até mesmo no quesito punições, já que os infratores nas partidas eram punidos com suspensões que os impediam de participar dos demais jogos de um determinado campeonato. Tais características personificaram na Makana Football Association os principais anseios da entidade reguladora do futebol no mundo e, como forma de reconhecimento, a FIFA promoveu, em 2007, a MFA a membro de honra da Federação.

A simpatia da FIFA em relação ao filme No futebol, nasce uma esperança fica evidenciada por conta da pré-estreia deste em Zurique, que contou com a presença da cúpula diretiva da instituição. A impressão deixada pela obra foi bastante positiva e referendada no comentário de Joseph Blatter ${ }^{42}$, ao falar do filme como um belo projeto que trata da dignidade, do respeito e da esperança, o que, nesse sentido, deixa a FIFA orgulhosa em apoiá-lo. Após o sucesso da pré-apresentação, a entidade decidiu incluí-lo na programação oficial do sorteio preliminar da Copa do Mundo de 2010, realizado em Durban, na própria África do Sul, em 13 de novembro de 2007.

41 GINZBURG, C. Mitos, emblemas, sinais: morfologia e história, op. cit.

42 PRESS RELEASES. More Than Just a Game, op. cit. 


\section{Um enredo de superação: uma prisão, seus prisioneiros e ofutebol}

Apresentado o caráter valorativo da produção, até os mais desatentos espectadores poderiam perceber a proximidade entre o conteúdo do filme e a realização da Copa do Mundo de Futebol de 2010 na África do Sul. Ora, além da simples proximidade espaço-temporal, o filme acentua a possibilidade de manifestação política/organizativa daqueles que foram presos e condenados por questionar, de diversas formas, o regime Apartheid, tendo como meio - e na sequência também como um fim - a prática e organização do futebol. A linha condutora dos depoimentos, à guisa de exemplo, acentuava uma conotação indireta de possibilidade libertária, como acentua Anthony Suze: "Se você visse como lutamos e fizemos campanhas para jogar futebol... Poder-se-ia equiparar isto à luta pela liberdade"43.

Sendo assim, centrado exclusivamente na presença da modalidade esportiva no cotidiano dos presos políticos, o longa-metragem ganha uma conotação unilateral e simplista. Homens dignos, defensores de uma das causas mais nobres, praticamente abandonaram seus ideais, empregando um tempo valioso na organização de uma complexa liga de futebol - inclusive com sistema de divisões, arbitragem com domínio das regras oficiais, clubes com dirigentes e torcedores e até a formação de um tribunal de justiça desportiva, que julgava os casos e os recursos mais variados. Tal politização, em se tratando de esporte, possivelmente reincide em uma despolitização macropolítica. De repente, questionar, sem motivo coerente, a derrota para uma equipe considerada fraca, tornou-se mais relevante do que manifestar-se contra o autoritarismo de muitos dos guardas daquele presídio. É o que fica claro em um episódio apresentado no filme.

Durante uma partida entre os dois extremos da Ilha - o Atlantic Raiders (considerado o melhor time) e o Blue Rocks (tido como a pior equipe) -, um lance causou muita polêmica: um gol do Blue Rocks, supostamente ilegal, foi validado pela arbitragem. Os jogadores do Atlantic Raiders protestaram veementemente contra o juiz, que não voltou atrás na 
decisão, validando o tento e argumentando ter seguido as normas da FIFA. As reclamações continuaram, até que o árbitro, pressionado, resolveu abandonar a partida. O jogo continuou com outro juiz, e os Blue Rocks formaram uma grande barreira impedindo os adversários de se aproximarem do gol. Enfim, a disputa terminou com a vitória do pior time da Ilha, "a equipe de velhos alquebrados". Inconformados com o resultado, alguns jogadores do Atlantic Raiders, liderados por Anthony Suze, apresentaram um recurso ao comitê disciplinar da Associação Makana, contestando a atuação do juiz e reivindicando a anulação da partida: "Ele saiu do campo. Isso não pode. É contra os regulamentos da FIFA, certo?"44, argumentava Suze. A partir do ocorrido, inúmeras audiências e sessões se sucederam. Após cinco meses de espera sem um resultado definitivo, os jogadores do Atlantic Raiders realizaram um protesto contra a Liga Makana, tida naquele momento como a entidade mais respeitada da prisão. Os integrantes da equipe derrotada deitaram-se no campo de jogo, minutos antes de uma partida, impedindo que esta fosse realizada. Pela primeira vez, a entidade era contestada. As partidas de futebol deixaram de acontecer, as relações ficaram desgastadas e o clima na prisão ficou tenso. Um sentimento de vergonha tomou conta dos outros detentos, principalmente quando um guarda da prisão os chamou de "selvagens". O protesto teve fim após alguns meses, quando os jogos voltaram a acontecer regularmente.

Também é evidenciada no filme certa crença - por sinal, desprovida de sentido - na qual, cegamente, os presos supervalorizavam as normas da FIFA, considerada exemplo de conduta, ética, liberdade e democracia aplicadas ao esporte. Fica a ideia implícita de que a gestão da entidade controladora do futebol mundial poderia ser simplesmente transposta à complexa realidade política local. Em depoimento, Anthony Suze declara:

Queríamos jogar de uma forma competitiva, para que se houvesse clubes, um clube pudesse planejar e outro se defender. Queríamos criar uma associação como a FIFA, queríamos competir e nessa competição criaríamos interesse. E por isso o futebol devia ser introduzido sistematicamente e com cuidado ${ }^{45}$. 
A preocupação da FIFA no sentido de evitar que atos racistas adentrem ao campo desportivo ${ }^{46}$ ocasionou diversas punições aos países geradores desse tipo de comportamento. A título de exemplo, pode-se citar a desqualificação da Alemanha na disputa da Copa do Mundo de 1950, realizada no Brasil, em consequência do regime nazista, e a desfiliação da própria África do Sul, em 1976, dos quadros da instituição, exatamente em decorrência da política do Apartheid, vetando, assim, a participação do país em disputas oficiais.

Recentemente, porém, alguns casos têm suscitado críticas à FIFA, devido às penas brandas impostas pela instituição, em episódios de racismo. Pode-se citar aqui o ocorrido na disputa entre Croácia e Inglaterra nas eliminatórias da Copa do Mundo de 2010, em Zagreb, na qual torcedores locais ofenderam o atacante inglês Emile Heskey com palavras de cunho racista. Nessa ocasião, a FIFA multou a Federação Croata de Futebol em apenas $£ 15.000$ pelos insultos racistas sofridos por Emile Heskey ${ }^{47}$ - valor este próximo a 27,7 mil euros.

Outro incidente desta natureza ocorreu na cidade de Zaragoza, em 25 de fevereiro de 2006, pela disputa do campeonato espanhol, envolvendo o atacante camaronês Samuel Eto'o. O referido atleta ameaçou se retirar do campo de jogo, no qual a equipe do Barcelona enfrentava o time do Real Zaragoza, após sofrer ofensas racistas de torcedores adversários, que imitavam sons de macacos a cada vez que o jogador tocava na bola. Tendo em vista que esse tipo de atitude racista era reincidente no estádio do Real Zaragoza, o próprio presidente da FIFA, Joseph Blatter, em declaração à BBC, qualificou

[...] como "ridícula" la multa de 9.000 euros impuesta al Real Zaragoza por los insultos racistas lanzados el pasado sábado a Samuel Eto'o en el estadio de La Romareda [...] Es tiempo de tomar medidas más duras contra este tipo de comportamientos ${ }^{48}$.

46 BOURDIEU, P. Coisas ditas. São Paulo: Brasiliense, 2004.

47 THE GUARDIAN. Liverpool fans to pay price for Atletico stadium ban. 15 out. 2008. Disponível em: <http://www.guardian.co.uk/football/2008/oct/15/liverpool-atleticomadrid>. Acesso em: 24/10/2009.

48 EL PAÍS.COM. El presidente de la FIFA califica como "ridícula" la multa al Zaragoza por los insultos a Eto'o. 03 mar. 2006. Disponível em: <http://www.elpais.com/articulo/deportes/presidente/ FIFA/califica/ridicula/multa/Zaragoza/insultos/Eto/elpepudep/20060303elpepudep_1/Tes $>$. Acesso em: 24/10/2009. 
Além deste, são dezenas de casos na Europa e alguns na América do Sul, como, por exemplo, o do argentino Desábato e do brasileiro "Grafite" no jogo entre as equipes do São Paulo e Quilmes, no qual Desábato ofendeu racialmente o jogador brasileiro ${ }^{49}$. Com o crescente aumento dessas atitudes bastante contestadas, o comitê executivo da FIFA prometeu adotar sansões menos brandas para ocorrências de racismo e discriminação nos próximos $\operatorname{anos}^{50}$. Considerando que as multas aplicadas aos clubes das torcidas e atletas agressores são irrisórias, levando-se em conta as cifras milionárias que envolvem o futebol, a FIFA visa implementar outros tipos de punições, dentre elas a perda de pontos, o descenso ou até a desclassificação em caso de reincidência.

Tendo em vista o posicionamento, no mínimo dúbio, da FIFA em relação aos casos de racismo, a ideia de que a entidade seria uma referência no combate ao regime segregacionista vigente na África do Sul, no período em que se passa o filme, pode ser questionado. Na visão dos principais protagonistas - Sedick Isaacs, Mark Shinners, Liso Sitoto, Marcus Solomon e Anthony Suze -, a FIFA era o modelo organizativo a ser seguido: "Se vocês obedecem às regras da FIFA, não podem dizer que eu estou errado" ${ }^{51}$ - argumento utilizado por um detento, na posição de juiz, durante uma partida de futebol disputada na Ilha. Entretanto, ressalta-se que a punição imposta à África do Sul (a desfiliação dos quadros da entidade) ocorreu somente em 1976; até então o país estava apenas suspenso das disputas internacionais - isso em uma época quando já era consensual a necessidade de uma intervenção mundial, por meio de sanções políticas, na tentativa de expurgar o regime Apartheid $^{52}$. E, novamente, os indícios conduzem à reflexão do porquê de um entendimento tão simplista por parte dos principais agentes/ protagonistas do filme.

O motivo pode ser porque as autoridades do presídio inicialmente não cederam à solicitação dos presos. Após quatro anos reivindicando

49 CAPRARO A. M.; CAVALCANTI, E. A. Racismo no futebol sul-americano: o caso Grafite versus Desábato. Motriz, Rio Claro, v. 15, n. 4, p. 741-748, out./dez. 2009.

50 Id., ibid.

51 AHMED, J.; SINGH, A. More Than Just a Game, op. cit.

52 HAVELANGE, J. João Havelange: vitória sobre o Apartheid, China Comunista na FIFA, televisão para a África de graça. 31 jan. 2010. Disponível em: $<$ http://www.tribunadaimprensa.com. br/?p=6434>. Acesso em: 03/02/2010. 
insistentemente o "privilégio" de praticar o futebol, os detentos, obviamente, comemoraram tal intento. Entretanto, na conversa em que o chefe da carceragem e o comandante da ilha deliberavam sobre tal assunto, ficaram evidenciadas as condições e os interesses dessa concessão. Nesta cena, o comandante da prisão revela que, em poucos dias, os "suíços" - entenda-se aqui: os comissários da Cruz Vermelha - fariam uma visita à ilha com o intuito de verificar as condições às quais os presos estavam submetidos. Nesse contexto, uma prática esportiva, como o futebol, serviria de argumento favorável (ou mesmo manipulador da realidade carcerária) ao sistema prisional violento imposto na prisão. É o que mostra a fala do capitão da Ilha de Robben, ao afirmar:

Eles estão obcecados com o futebol. Como crianças. Eles estão morrendo na pedreira. Quanto tempo vão durar? Nós não somos irracionais. Deixe que eles joguem! Eles pediram com educação. Convidaremos a Cruz Vermelha para observar tudo. Afinal, eles gostam de futebol na Suíça. Eu sei que eles gostam de chocolate. Daremos ao enviado de Genebra alguns chocolates e um jogo de futebol. Mas mostre homens musculosos. Saudáveis [...]. Em duas semanas ou três eles estarão exaustos. E tudo isto será esquecido. E insista que nós manteremos o controle. Nós estamos dando isto a eles. Eles não estão tirando isto de nós. É assim que funciona. A minha resposta é sim. Deixe que eles construam o campo e joguem $!^{53}$

O futebol praticado em Robben tornou-se a principal atividade de lazer dos detentos. As partidas aconteciam nos finais de semana, período em que os presos não trabalhavam na pedreira. No início, os jogos eram apenas disputas desprovidas de maior organização, contudo, o aumento da popularidade do esporte entre os presos ocasionou uma série de transformações. Diante disso, tal como exposto anteriormente, os detentos decidiram organizar uma Liga, cuja principal referência seriam as normas estabelecidas pela FIFA. Assim, houve a criação de divisões; as regras pautavam-se no estatuto da entidade internacional; elaborou-se um tribunal com competência para julgar casos de indisciplina; foram adotados juízes 
e impostas eleições para os cargos diretivos - estava fundada a Makana Football Association (MFA).

Tal organização burocrática ocupava parte considerável do tempo dos envolvidos, como evidenciado em algumas passagens do filme. $\mathrm{O}$ período ocioso dos presidiários era dedicado a um denso estudo dos estatutos da FIFA, e todas as decisões acerca da Liga seguiam os moldes da instituição internacional. Como relata Mark Shinners: “[...] De domingo a quarta analisávamos. Na quarta planejávamos o sábado. [...] Nós ficávamos muito ansiosos" ${ }^{\prime 5}$. Mesmo sob o regime de trabalho forçado na pedreira, as conversas a respeito do futebol eram constantes. Durante as noites, nas celas coletivas, eram realizados os julgamentos referentes a atos de indisciplina ocorridos nas partidas. Havia, ainda, os treinamentos, nos quais os detentos aprimoravam as condições técnica e física.

Outra importante característica da MFA foi a supressão ideológica e partidária. Era consenso, entre os integrantes da Liga, que o futebol não deveria se sujeitar a qualquer influência resultante de preferências partidárias ou questões ideológicas, tal como preconizado pelo ideário da FIFA. Como afirmado por Anthony Suze, em depoimento no filme: "Queríamos jogar, não nos meter em política. Nossos objetivos eram claros: primeiro, promover e jogar o futebol; segundo, difundir o esporte e a camaradagem na ilha; terceiro, assegurar que toda pessoa fisicamente capaz aprendesse a jogar futebol na Ilha" 55 .

Rapidamente, o futebol se tornou elemento central na vida da maioria dos detentos da Ilha, ao passo que a luta política pela igualdade racial, com todos os desdobramentos políticos, sociais, e econômicos, ficava relegada a um segundo plano. Evidência esta confirmada pela assertiva de um dos prisioneiros praticantes do esporte: "Eles vivem falando de uma frente unida e de jogos servindo ao futebol, e não à política. E o que eles fazem no momento em que nos posicionamos? ANC de um lado e PAC do outro. [...] Eu era contra escolher times segundo organizações políticas [... ${ }^{\prime \prime 56}$. Nesse sentido, o esporte detinha duas representações distintas: por um lado, demonstrava a capacidade organizativa dos presos na gestão da Liga

56 Id., ibid. 
Makana, entendida pelos protagonistas como uma vitória sobre a repressão vigente; por outro, tal atividade correspondia principalmente aos interesses dos mandatários da prisão, que perceberam no futebol um poderoso aliado, já que este garantia a obediência, a docilidade e a submissão dos detentos em relação às regras impostas pelo regime.

Logo após o depoimento de Liso Sitoto, no qual diz: "Eu acho que não estou errado em dizer que o futebol salvou muitos de nós na Ilha" 57 , acontece a cena na qual alguns detentos que se dirigiam ao campo para disputar uma partida de futebol presenciam um guarda espancando um presidiário negro. Os detentos não reagem, muito pelo contrário: lamentosos e passivos diante da situação, eles apenas seguem naturalmente para o campo de futebol, onde o sentimento dos minutos anteriores se desfaz e um dos prisioneiros abre os braços fazendo menção à liberdade.

A prisão da Ilha de Robben era dividida em setores: cada um confinava os presos de acordo com as características de seus delitos ou seu grau de influência. As celas coletivas, por exemplo, abrigavam detentos que, de certa forma, não representavam perigo à segurança local e cujas penas eram mais brandas ${ }^{58}$. Ressalta-se aqui que os cinco protagonistas da obra em questão faziam parte deste grupo, o qual era majoritário. Os detentos cujas penas eram mais longas ou que fossem considerados influentes, ou, ainda, que representassem algum perigo à segurança do presídio, eram alojados na ala de isolamento, a $S e c ̧ a ̃ o ~ B$. Esta ala era provida de uma segurança especial e os detentos não participavam das atividades comuns aos outros presos. Nesta seção, estavam encarcerados alguns dos principais nomes oposicionistas ao regime, como Nelson Mandela, Ahmed Kathrada, Walter Sisulu, Raymond Mhlaba, entre outros. Havia, também, o setor das celas solitárias, que comumente era utilizado como forma de punição a atos de indisciplina ou desobediência ${ }^{59}$.

Essa separação por setores ficou evidenciada em uma cena do filme, em que Mandela, Kathrada e Sisulu são avistados pelos prisioneiros das celas coletivas, durante uma partida de futebol. A reação foi imediata e a partida interrompida, os presos comuns iniciaram uma manifestação de

57 Id., ibid.

58 MAHARAJ, M. (Ed.). Mandela: retrato autorizado, op. cit.

59 Id., ibid. 
apoio, gritando os nomes daqueles detentos, porém, a tentativa de aproximação foi logo rechaçada pela segurança do presídio. Pouco tempo após o episódio, foi construído um muro que separou definitivamente as áreas de isolamento das áreas comuns à maioria dos detentos. Essa foi a única ocasião, no filme, em que os detentos influentes foram vistos pela maioria dos presos. Tal aparição marcou a primeira manifestação de indisciplina com teor político, por parte dos presos das celas coletivas, desde a chegada dos protagonistas à Ilha de Robben. A construção do muro era um indício de que a segurança e a obediência na prisão estariam garantidas com o isolamento dos líderes do movimento anti-Apartheid, bem como com a manutenção dos campeonatos organizados pela Makana Football Association.

E, assim, até o desfecho do filme, com a liberdade de um dos prisioneiros, após o cumprimento da sua pena, aponta para um sentimento de saudosismo. Este prisioneiro - Anthony Suze -, ao embarcar no barco que o levaria ao continente, contempla o horizonte e, em seguida, se depara com jovens uniformizados que chegam à prisão da Ilha de Robben. Os novos encarcerados aparecem acorrentados uns aos outros e chutando uma pedra entre si - o que remete não só à ideia de que poderão se beneficiar do direito de jogar futebol, mas também à importância atribuída a tal conquista. $\mathrm{O}$ filme encerra com o resultado do sorteio da FIFA, anunciando a África do Sul como país-sede da Copa do Mundo de 2010.

Ora, a produção em pauta reproduz os aspectos do contexto em que está inserido e, não obstante, o "filme histórico" secundário, aquele que discursa sobre o passado, acaba por refletir os interesses da sociedade (presente) em que se insere ${ }^{60}$. Nesse sentido, a obra cinematográfica em foco nos incita a valorizar aquilo que foi exposto em relação ao futebol na prisão, ou seja, é determinada reconstrução artística de um determinado episódio e não uma representação fidedigna daquilo que ocorreu. 


\section{Considerações finais}

As pistas e indícios - captadas nas referências bibliográficas sobre o regime Apartheid; nas entrevistas de diretores, produtores e representantes da FIFA; nas matérias jornalísticas, material de divulgação da obra e nas críticas - apontam para um sentido de contexto bastante pontual da obra. A produção é fruto da sua própria época. Assim, mesmo narrando um episódio da história recente da África do Sul, o filme No futebol, nasce uma esperança mantém vínculos mais específicos: o pleito bem-sucedido e o processo de organização da Copa do Mundo de Futebol, no ano de 2010.

Por esse motivo, o ocorrido na prisão da Ilha de Robben, por meio da (re)estruturação do enredo, superdimensiona a prática do futebol entre os presos e até mesmo o grau de importância destes no processo geral de tensões ocorridas durante o regime segregacionista em questão. Novamente, pistas e indícios desvelam que os principais agentes presos, como o próprio Nelson Mandela, estavam encarcerados em outro bloco, com medidas de segurança mais rígidas, alguns até isolados, pois eram considerados moralmente perigosos para manter contato direto com os demais presos. A Makana Football Association era, sobretudo, um benefício cedido pela direção carcerária aos presos de baixo risco - com a finalidade de aparentar o bem-estar destes para as instituições internacionais, que fiscalizavam as condições dispostas aos condenados na Ilha, assim como oferecer uma forma de entretenimento que minimizasse o engajamento sociorracial contra o sistema vigente.

A oposição da FIFA ao regime é bastante valorizada na produção cinematográfica em questão, na mesma proporção em que é questionável ao se analisar os fatos. Mesmo suspendendo parcialmente o país dos campeonatos internacionais da modalidade, a partir de 1961, a punição de exclusão dos quadros da entidade ocorreu apenas no ano de 1976. Isto é, no período em que se ambienta o filme - entre os anos de 1961 e 1976 -, a FIFA permitiu que o selecionado africano participasse de alguns torneios internacionais, sendo representado por uma minoria branca ${ }^{61}$.

61 HAVELANGE. João Havelange: vitória sobre o Apartheid, China Comunista na FIFA, televisão para a África de graça, op. cit. 
Nesse sentido, aumentando a escala de análise ${ }^{62}$, com a finalidade de inserir a Makana Football Association no contexto sul-africano da década de 1960, é possível concluir que seu caráter era moralizador e doutrinador - os próprios agentes carcerários, por exemplo, forneceram os manuais com as regras e regulamentos da FIFA -, entretanto, esta é uma ideia pouca explorada no filme.

Enfim, como "gênero de fronteira", já que apresenta a interpretação cênica de um determinado fato histórico, somada a depoimentos dos principais envolvidos, o filme é tendencioso ao atender interesses recentes. Por outro lado, como forma de expressão artística, não deixa de ser uma bela montagem, tendo em vista o teor do enredo e, principalmente, a harmonia entre as interpretações e os depoimentos, a ponto de tornar complexo o discernimento entre história e ficção.

Recebido em março de 2011. Aprovado em abril de 2011. 